\title{
House Dust Mite Allergy in Kolkata Metropolis in Response to Change in Lifestyle
}

\section{Saha GK*}

Department of Zoology, University of Calcutta, India

*Corresponding author: Goutam Kumar Saha, Department of Zoology, University of Calcutta \& Director Institute of Agricultural Science, 35 Ballygunge Circular Road, Kolkata-700019, India, Email: gkszoo@gmail.com

\section{Review Article}

Volume 2 Issue 6

Received Date: November 27, 2019

Published Date: December 12, 2019

DOI: $10.23880 /$ izab-16000189

\section{Abstract}

House dust allergy is a fairly common problem among sensitive individuals, resulting in various types of allergic manifestations like allergic rhinitis, atopic eczema, bronchial asthma etc. Although the prevalence of allergic diseases is more common in westernized and developed countries, the incidence is increasing at a rapid pace in developing countries like India too. However, data in this regard is still fragmentary except few scattered information in Indian context. In a rough estimate, in India, 250 million people are suffering from one or more allergic manifestations and the country is the home to around 15-20 million asthmatics. To offer the patients with best possible diagnosis and treatment, the detection of offending allergens are of prime importance. At the same time, early detection of individuals who are genetically at risk of developing allergy to readily available indoor allergens is also an essential element to adopt effective avoidance strategies and to design appropriate therapies. House dust is a complex mixture of substances of plant and animal origin and consists of animal and human dander, debris from wool, feathers, hairs, insects, cotton, silk, jute and synthetic fibers, carpets, beddings, furniture and upholstery, fungal spores, bacteria, microorganisms and shedding from other house hold articles and long been known to cause sneezing and wheezing in sensitive subjects. However, the exact nature of the principal allergen in house dust was unknown for quite a long time. It is now well documented that the mites of the genus Dermatophagoides are the most potent allergens in house dust responsible for allergic manifestations. During last more than 30 years, studies on different aspects of house dust mite allergy have been carried out on Kolkata population including entomological, clinical and immunological findings. The study indicates that the house dust sample contains an allergen, secreted and excreted by the house dust mites and inhalation of this allergen along with dust particles initiates allergic manifestations. The genus Dermatophagoides alone constituted $60 \%$ of the total acarine fauna, predominated by D. pteronyssinus (47\%) followed by $D$. farinae and interestingly both the mite species coexisted in the same habitat. Seasonal trend indicates mite counts was higher in pre-monsoon and minimum during winter and are 
abundant in beds than elsewhere in the house and mostly associated with pillows, blankets, mattresses, padded furniture and carpeted floors etc. and preferably feed on human dander. The study indicates that more than $80 \%$ allergic asthma patients residing in Kolkata metropolitan areas are sensitive to dust mites, especially genus Dermatophagoides Spp. as evident from skin prick test and detection of allergen specific IgE antibodies by Immuno Cap system. It is assumed that changes in life style including diet and dietary habits, acquisition of western lifestyle, low standard of indoor environment, increasing air pollution and over all intolerable psychological stress are blamed for such an increased occurrence and frequent recurrences of allergic manifestations in Kolkata metropolitan areas. Increase use of padded furniture, sofa sets, heavy curtains, wall to wall carpeting, blankets without any cover instead of traditional quilt, use of foam mattress instead of conventional cotton mattress and soft toys favour the growth and multiplication of house dust mites, which ultimately increases the chances and duration of exposure to those indoor allergens. In more than $70 \%$ cases these may be attributed to the metamorphic change in lifestyle.

Keywords: Dermatophagoides; Lifestyle Change; Asthma; Stress; IgE; RAST; Immuno Cap System

\section{Introduction}

House dust allergy being a serious threat among sensitive individuals, results in various types of allergic manifestations like allergic rhinitis, atopic eczema, bronchial asthma etc. About $4 \%$ of the world population suffers from different types of allergic disorders. The nasobronchial passage of susceptible individuals are sensitive to various external substances namely pollens, moulds, feathers, furs, animal dander, dust and house dust mites etc., repeated exposure to which may initiate allergic manifestations in sensitive individuals.

An increasing trend in the incidence of different respiratory allergic disorders including bronchial asthma have been reported from different parts of the world especially from developing countries like India, because of diverse factors such as change in ambient air quality, increased air pollution, metamorphic change in living habits and lifestyle, food and feeding habits and unexpected climate change. Several aeroallergens like pollens, fungi, etc. present in the air play a pivotal role in the pathogenesis of several allergic complaints including bronchial asthma. Although the prevalence of allergic diseases are more common in westernized and developed countries, the incidence is increasing at a rapid pace in developing countries including India, becoming doubled, tripled and even quadrupled in the last few decades. However, data in this regard is still fragmentary except few scattered information in Indian context. In a rough estimate 250 million people are suffering from one or more allergic manifestations in India. India is the home to around 15-20 million asthmatics and it is increasing day by day. To offer the patients with best possible diagnosis and treatment, the detection of offending allergens are of prime importance. At the same time, early detection of individuals who are genetically at risk of developing allergy to readily available indoor allergens is also an essential element to adopt effective avoidance strategies and to design appropriate therapies.

House dust is a complex mixture of substances of plant and animal origin and consists of animal and human dander, debris from wool, feathers, hairs, insects, cotton, silk, jute and synthetic fibers, carpets, beddings, furniture and upholstery and apparently responsible for sneezing and wheezing in most of the individuals. Besides, fungal spores, bacteria, microorganisms and shedding from other house hold articles also contribute to its composition. The association between inhalation of house dust and initiation of nasobronchial allergic manifestations like sneezing and wheezing in sensitive subjects has long been suspected. However, the exact nature of the principal allergen in house dust was unknown for quite a long time [1,2]. highlighted the role of house dust in causing respiratory allergy and suggested the presence of distinct allergen in it. It was Voorhorst, et al. (1964) [3] who first pointed out that house dust mites belonging to the genus Dermatophagoides of the Family Pyroglyphidae are the most potent allergen in house dust responsible for various allergic manifestations. Subsequently allergy skin tests and nasal and bronchial 
challenge tests have clearly established that pyroglyphid mites are chiefly responsible for house dust allergy $[3,4]$. These findings were further confirmed by the estimation of total serum IgE level and detection of mite specific IgE antibodies present in patient's sera [5-7]. In India, Shivpuri, et al. [8] first of all claimed that the mite is perhaps the sole potent allergen responsible for precipitation of attack of bronchial asthma. Since then the studies on house dust mite fauna and their probable role on the aetiopathogenesis of different allergic disorders have been reported from different parts of India [9-24]. From Kolkata, Saha, [20-22] and Saha, et al. [23,24] reported that more than $88 \%$ of the asthmatic patients are sensitive to Dermatophagoides mites as evidenced from analysis of house dust, allergy skin test and detection of allergen specific IgE antibodies by RAST method. Besides Euroglyphus maynei, Tyrophagus putrescentiae, Acarus siro and Glyciphagus domesticus are also known to produce allergens in house dust though with relatively low potency [25].

Mites (Arthropoda: Arachnida: Acari) are minute (0.5 to $2 \mathrm{~mm}$ in length) and are characterized by the absence of antennae and mandibles and the presence of simple eyes, four pairs of walking legs and two pairs of specialized mouthparts chelicerae and pedipalpi. More than 200 families, 1700 genera and 30,000 species have already been described and an estimated half a million species are on the line to increase the taxonomic burden of the group [26].
A vast majority of the identified mites are generally harmless to human. On the other hand only 250 mite species are considered to be associated with the health related problems of humans and domestic animals, thus inflicting great economic loss [27]. Due to their tremendous economic importance both as pest of agricultural crops as well as in veterinary and human health, the group has created worldwide attention among common people and medical entomologists and acarologists. Although majority of mite species are free living, a large number of them are known to parasitize both plants and animals including human beings. They may infest both internal organs of humans, preferably respiratory tract, lungs, intestine, ear passage etc. $[28,29]$ as well as outer skin [30-32]. At the same time, they often act as reservoir and or vector of several serious pathogens of human and veterinary importance [33-36].

These tiny and delicate organisms exhibit extreme diversity in structure, habitat and behavior. Among them there is a taxonomically and ecologically defined assemblage called "House Dust Mite" chiefly consisting of Dermatophagoides spp. They are free living and occupy every niche of the house, being more abundant in beds than elsewhere in the house, because beds are rich in human scales on which they feed $[37,38]$ and provide the ideal microclimate such as temperature and humidity etc. Among several species of Dermatophagoides mites, $D$. pteronyssinus and D. farinae are most common and ubiquitous in distribution [39] as shown in Figure 1.

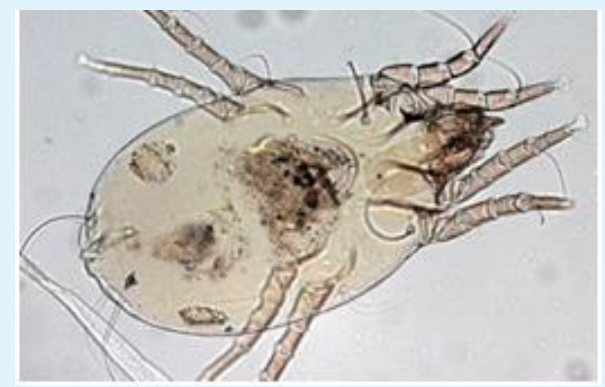

A

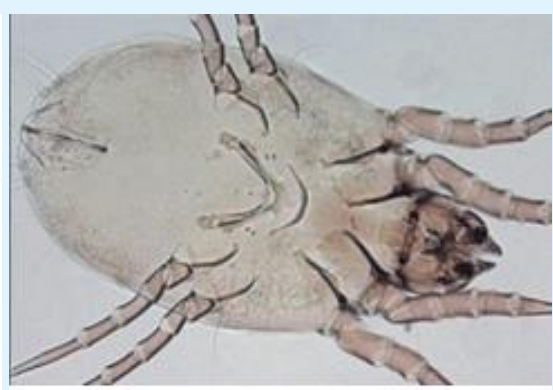

B

Figure 1: Common house dust mites: A: D. pteronyssinus (European House Dust Mite) and B: D. farinae (American House Dust Mite).

Allergy to house dust mites particularly the genus Dermatophagoides is a common feature in Kolkata metropolitan areas with a steady increase in their incidence in the recent past. A two fold increase in the prevalence of naso-bronchial allergic manifestations has been noted from the urban settings of Kolkata during last few decades. In India, mite associated allergy is a poorly researched area with insufficient quantum of knowledge. It is now well documented that the mites of the genus Dermatophagoides are the most potent allergens in house 
dust responsible for allergic manifestations. During last 30 years, we have studied the house dust mite fauna of West Bengal [7,14,15,17,20-24,40-51,52-55]. A total of fourteen districts of West Bengal including Kolkata metropolis have been searched for mite fauna. A total of 68 species of mites belonging to 25 families under 44 genera and three orders namely, Astigmata, Prostigmata and Mesostigmata have been reported including a good number of unidentified cryptostigmatids. Among them six species appeared to be new to science while another 20 species were reported for the first time from Indian house dust samples. It is interesting to note that maximum number of mite species (47) were isolated from dust samples of Kolkata followed by Burdwan (40) and 24 Parganas (33) and least (6) from Birbhum district of West Bengal [44]. The genus Dermatophagoides alone constituted $60 \%$ of the total acarine fauna, predominated by $D$. pteronyssinus ( $47 \%$ ) followed by $D$. farinae. Both $D$. pterinyssinus (DP) and D. farinae (DF) coexisted in the same habitat and maximum number of mites isolated from an individual dust sample was $13750 / \mathrm{gm}$ of dust. Seasonal trend indicates mite count was higher in premonsoon and minimum during winter and are abundant in beds than elsewhere in the house and mostly associated with pillows, blankets, mattresses, padded furniture and carpeted floors etc (Figure 2) and preferably feed on human danders. Tovey, et al. [56] showed that more than $95 \%$ of the allergens accumulating in mite cultures was associated with faecal particles and emphasized their role as the major source of house dust allergens. Excrement particles obtained from mite's intestines by microsurgery were found highly allergenic in patients, allergic to house dust as was reported also by Halmai, et al. and Muto, et al. [57,58] emphasized the role of house dust mite in the dwelling houses as a trigger of asthmatic attack, by measuring Anti-DP specific IgE antibodies and opined that allergy to house dust mites is a significant feature in the disease pathogenesis and is associated with modifications to traditional life styles by the recent introduction of blankets, foam mattresses and changes in sleeping habits that promoted a more fertile environment for growth and multiplication of mites. Preliminary screening through Skin Prick Test showed 83\% patients reacted positively towards allergens of mites (either DP or DF), 92\% patients had elevated levels of serum IgE and the mean value higher than control sera $(\mathrm{p}<<0.001) .85 \%$ patients of the study group showed allergen specific IgE antibodies against house dust and Dermatophagoides mites. The study indicates that more than $80 \%$ allergic asthma patients residing in Kolkata metropolitan areas are sensitive to dust mites, specially genus Dermatophagoides
Spp. as evident from skin prick test and detection of allergen specific IgE antibodies by Immuno Cap system.

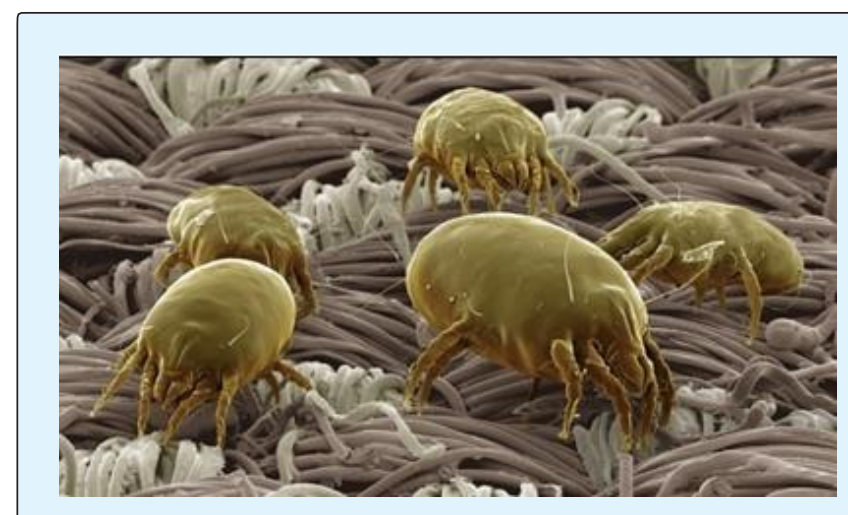

Figure 2: Mites on the blanket.

Estimation of total serum IgE level and detection of specific IgE antibodies against offending allergen, by Radio Immuno Assay (RIA), as an alternative and confirmative method for diagnosis of extrinsic allergy had been reported by Lal, et al. [9]. They estimated total and specific serum IgE concentration in patients of bronchial asthma in relation to house dust and house dust mites. Estimation of serum immunoglobulins including $\operatorname{IgE}$ in the sera and bronchial aspirates of children and adults with wheezy bronchitis, bronchial asthma and pulmonary eosinophilia was made by different authors $[7,19,20,59$ 61].

Though specific serum IgE antibodies against the offending allergens (pollen, Aspergillus and house dust) in patient of bronchial asthma had been estimated $[16,60$ 62], information with regard to the level of specific serum IgE antibodies against house dust, D. pteronysinus and $D$. farinae mite antigens was lacking for quite a long time in Indian context. Batabayal, et al. [62] however, presented some data on the diagnosis of allergic disorders involving skin testing, analysis of the serum for total $\operatorname{IgE}$ and allergen specific IgE antibodies against pollen grains and total house dust. Khatua, et al. [60] made an immunological study of bronchial asthma in children between 1 to 5 years of age, wherein a relation between asthma with total and specific IgE and the common allergens (mostly pollens) responsible to precipitate the attack was made. Saha, [20,21,22] Saha, et al. [63] and Poddar, et al. $[46,47]$ have carried out extensive research on different aspects of dust mite allergy in Kolkata, India including entomological, clinical and immunological parameters in a comprehensive manner since more than 


\section{International Journal of Zoology and Animal Biology}

thirty years and established the role of house dust mites in house dust allergy [64].

\section{Allergy an Upcoming Lifestyle Disorder}

There are good numbers of diseases which may be initiated, maintained, aggravated and ultimately governed by lifestyle factors like cancer, cardiac disorders, diabetes, orthopedic problems, back pain etc. popularly known as lifestyle disorders. During recent past the most upcoming events related to changes in lifestyle pattern which has come to the surface in an unprecedented manner particularly in developing countries like India are different allergic manifestations due to inhalation of mite laden dust particles. The concern is that the incidence of allergic disorders are increasing in developing countries too, becoming doubled, even tripled in the last few decades. Interestingly, $75 \%$ of these are traced to change in lifestyle such as

$>$ Acquisition of Western lifestyle,

$>$ Changes in diet \& dietary habits,

$>$ Consumption of processed food unhealthy, full of preservatives,

Increased air pollution, poor air quality, cities in particular.

$>$ Booming beauty business (indiscriminate use of cosmetics, lotions \& creams).

$>$ Intolerable psychological stress.

\section{At Home}

$>$ Use of foam mattresses instead of traditional cotton mattresses.

$>$ Use of blanket without any cover instead of traditional quilt

$>$ Wall to wall room carpets

$>$ Use of soft toys, heavy curtains, upholstery and padded furniture.

All these factors support the growth and multiplication of house dust mites inside the bedroom, which ultimately increases the chance and duration of exposure to that indoor allergen.

\section{Control Measures}

There is no simple and effective way to cure mite borne allergic diseases, but the symptoms may be relieved or minimized and in best cases eliminated with the adoption of combination of suitable preventive as well as curative measures. If the patient can be maintained relatively free of symptoms, the chances of increasing the tolerance with time will improve and the risk of developing new allergies minimizes. However, the tendency towards spontaneous development of tolerance varies markedly with age and with the type of symptoms and allergens.

\section{Environmental Management}

Environmental control or management of entire home especially bedroom and bed in particular to minimize mite exposure.

- Proper sanitation, hygiene and a general cleanliness of the bed and bedroom should be recommended.

- Avoidance of suspected offending allergens as far as practicable.

- House dust mites seem to thrive best on human skin scales; supply of food materials to the mites should be restricted.

- Periodic shaking of bedroll and frequent washing of bed sheets and blankets should be done.

- Avoid use of carpets, foam mattresses and other padded furniture in the patient's bedroom.

- Reduction of dampness and non-availability of moisture drastically reduces mite population. Keeping indoor moisture low (30-40\%). Use an air conditioner or dehumidifier to decrease the humidity.

- To reduce mite population, various acaricides have been recommended such as benzyl benzoate, pirimiphos methyl or lindane. Lindane impregnated in cloth @ $10 \mathrm{gm} / \mathrm{m}^{2}$ can effectively kill cent percent mites when exposed to it for 155 days.

- Complete encasement of beds with plastic covers.

- Keep pets out of the bed-room.

- Applying tannic acid solution to neutralize the allergen in mite droppings.

\section{Recommendation}

It is assumed that changes in lifestyle including diet and dietary habits, acquisition of western lifestyle, low standard of indoor environment, increasing air pollution and over all intolerable psychological stress are blamed for such an increased occurrence and frequent recurrences of allergic manifestations in Kolkata metropolitan areas. Besides, increase use of padded furniture, sofa sets, heavy curtains, wall to wall carpeting, blankets without any cover instead of traditional quilt, use of foam mattress instead of conventional cotton mattress and soft toys favor the growth and multiplication of house dust mites and thus chances of inhalation of mites along with the dust particles are increased for a longer period of time. Thus, in more than $70 \%$ cases these may be attributed to the metamorphic change in lifestyle. 


\section{International Journal of Zoology and Animal Biology}

Change your lifestyle to improve allergies. Simply follow some good health practices:

$>$ Bedroom should be under environmental management

> Eat a well-balanced diet avoid unhealthy diet specially junk and processed food to avoid obesity. It is now well documented that diet is related to weight and affects asthma. Children, who mostly eat a "Western" diet with high amounts of fat and processed foods, have been shown to have higher asthma prevalence rates.

$>$ Minimise stress and anxiety

Dxercise regularly. - be physically active, avoid sedentary lifestyle and obesity.

\section{Acknowledgements}

Author expresses his deep sense of gratitude to Late Prof. D. K. Choudhuri, Prof. Amiya Kr. Hati, Dr. Neelam Tandon, Dr. A. Modak, Dr. Arijit Das, Dr. Saibal Maitra, Dr. Indrani Choudhuri. Author is also thankful to Dr. Gautam Aditya, Dr. Amlan Ghosh, Dr. Sanjay Podder, Dr. Soumi Nandi, Dr. Shampa Dutta, Dr. Debarati Dey, Dr. Swarnali Mukherjee, Arghya and Priti for providing necessary data. Special thanks to management and staff members of Allergy and Asthma Research Centre, Kolkata.

\section{References}

1. Kern RA (1921) Dust sensitization in bronchial asthma. Med Clin North Am 5: 751-758.

2. Cooke RA (1922) Studies in specific hypersensitiveness, IV. New etiologic factors in bronchial asthma. J Immunol 7: 147-162.

3. Voorhorst R, Boezeman S, Spieksma FT (1964) Is a mite (Dermatophagoides sp.) the producer of house dust allergen?. Allergy Asthma 10: 329-334.

4. Pepys J, Chan M, Hargreeve FE (1968) Mites and house dust allergy. Lancet 1(7555): 1270-1272.

5. Aas K, Johansson SGO (1971) The radioallergosorbent test in the in-vitro diagnosis or multiple reaginic allergy. J Allergy Clin Immunol 48: 134-142.

6. Dockhorn R (1982) Using the RAST with an overview of clinical significance. Ann Allergy 49: 1-8.

7. Saha GK, Modak A, Batabayal SK, Choudhuri DK, Maitra SB, et al. (1989) Clinical significance of IgE in bronchial asthma. J Indian Med Assoc 87(7): 155-157.

8. Shivpuri DN, Agarwal MK (1971) Common precipitating causes of attacks of bronchial asthma in
174 patients. Proceedings of the 26th National Conference on Tuberculosis and Chest Diseases pp: 382.

9. Lal MA, Dasgupta A, Pande JN, Nayer E, Guleria JS (1973) Clinical significance of skin reaction to mite extract in individuals with bronchial asthma. Ind J Med Res 61(5): 672-675.

10. Nayar E, Lal M, Das A, Gupta (1974) The prevalence of mite Dermatophagoides pteronyssinus and its association with house dust allergy. Indian J Med Res 62 (1): 11-14.

11. Dar N, Gupta VK (1979) Studies on the house dust mites of India and their role in causation of bronchial asthma and allergic rhinitis. Part-I. The mites. Orient Insects 13(3-4): 261-298.

12. Shivpuri DN (1981) House dust mite allergy in India. Aspects of Allergy and Applied Immunology 14: 1935.

13. Jamil Z, Maurya R (1981) Exploration of the requisities for the mass culture of Dermatophagoides farinae. Contributions in Acarology in India. 27: 111115.

14. Tandon N, Batabyal SK, Saha GK (1988) Dust mites in relation to naso-bronchial allergy in Calcutta-a preliminary report. Indian J Allergy Asthma Immunol 2(1): 11-14.

15. Tandon N, Mitra SB, Saha GK (1990) Role of cockroaches in allergy to house dust in Calcutta, India. Ann Allergy 64(2 pt 1): 155-157.

16. Roy S, Sharma A, Chetty A (1987) Skin test and RAST in children allergic to common allergens. Indian J Pediatr 5: 437-440.

17. Modak A, Saha GK, Tandon N (1987) House dust mite fauna in asthmatics with special reference to socioeconomic status of the patients. Indian Med Gaz 112(10): 346-349.

18. Modak A, Saha GK, Tandon N (1991) Dust mite fauna in houses of bronchial asthma patients-comparative study of three zones of West Bengal (India). Entomon 16: $115-120$.

19. Modak A, Saha GK, Gupta SK (1995) Occurrence of some uncommon dust mites from the houses of respiratory allergic patients in West Bengal, India. J Acarol 13: 29-34. 


\section{International Journal of Zoology and Animal Biology}

20. Saha GK (1993) House dust mite allergy in Calcutta, India: Evaluation by RAST. Ann. Allergy 70(4): 305309.

21. Saha GK (1994) Relationship between Dermatophagoides mite density and specific immune response in asthmatic patients. Ann Allergy 73(5): 429-433.

22. Saha GK (1997) House dust mite sensitivity among rural and urban asthmatics of West Bengal, India: a comparison, Aerobiologia 13(4): 269-273.

23. Saha GK, Modak A, Tandon N (1995) Prevalence of house dust mites (Dermatophagoides spp.) in homes of asthmatic patients of Calcutta. Ann Entomol 12: 2125.

24. Saha GK, Modak A, Tandon N, Choudhuri DK (1995) The evaluation of skin prick test in house dust mite allergy in Calcutta, India. Trop Geogr Med 47(6): 278281.

25. Voorhorst R, Spieksma FM (1973) House dust atopy and the house dust mite Dermatophagoides. Allergol Immunopathol 1(1): 13-24.

26. Krantz GW (1978) A manual of Acarology 2nd (Edn.), Oregon State University, Corvallis.

27. Hoy MA (2009) The predatory mite Metaseiuleus occidentalis: mitey small and mitey large genome. Bioessays 31(5): 581-590.

28. Bernhard K, Karg W, Steinbrink H (1986) House dust mites in bed dust and on the body. Angew Parasitol 27(1): 49-52.

29. Krametter Froetscher R, Leschnik M, Hoegler S (2006) Occurrence of ear-mite Raillietia auris in cattle in Austria. Vet J 17(1): 186-188.

30. Rack G (1971) Cheyletiella yasguri Smiley, 1965 (Acarina, Cheyletiellidae), an optional human pathogenic parasite of the dog. Journal of Parasite Science 36(4): 321-334.

31. Numata T, Yamamoto S, Yamura T (1979) The role of mite allergen in chronic urticaria. Ann Allerg 43(6): 356-358.

32. Yoshikaya M, Hanaoka K, Yamada Y (1983) Experimental proof of itching papules caused by Cheyletus malaccensis (Oudeman). Ann Rep Tokyo Metrop Res Lab Publ Health 34: 264-276.
33. Mulvey PM (1972) Cot death survey. Anaphylaxis and the house dust mite. Med J Aust 2(22): 1240-1244.

34. Fujimoto T, Kato H, Ichiose E (1982) Immune complex and mite antigen in Kawasaki disease. Lancet 2: 980-981.

35. Yamashita T, Kasuya S, Noda N, Nagano I, Kang JS (1994) Transmission of Rickettsia tsutsugamushi strains among humans, wild rodents, and trombiculid mitesin in an area of Japan in which tsutsugamushi disease is newly endemic. J Clin Microbiol 32(11): 2780-2785.

36. Kabeya H, Colborn JM, Y Bai (2010) Detection of Bartonella tamiae DNA in ectoparasite from rodents in Thailand and their sequence similarity with bacterial cultures from Thai patients. Vector-borne Zoonotic Dis 10(5): 429-434.

37. Spieksma (1967) Occurrence and properties of the house dust mite Dermatophagoides pteronyssinus. Int Rhinology 5: 162-167.

38. Bronswijk JEMH, Sinha RN (1971) Pyroglyphid mites (Acari) and house dust allergy. J Allergy 47: 31-52.

39. Wharton GW (1976) House dust mites. J Med Entomol 12(6): 577-621.

40. Modak A, Saha GK, Gupta SK (2003) Faunal diversity and habitat preference of house dust mites of West Bengal in relation to Nasobronchial allergic disorders. Rec Zool Surv India 102(1\&2): 1-11.

41. Modak A, Saha GK, Tandon N (2004) Faunal diversity \& habitat preference of house dust mites of West Bengal in relation to nasobranchial allergic disorders. Rec Zool Surv India 102(1-2): 137-146.

42. Modak A, Saha GK (2002) Effect of certain socioecological factors on the population density of house dust mites in mattress dust of asthmatic patients of Calcutta, India. Aerobiologia 18(3-4): 239-244.

43. Saha GK (2002) House dust allergy- an environmental enigma. In: Recent Advances in Life Sciences. University of Calcutta pp: 11-13.

44. Saha GK (2005) House dust mite allergy-an environmental enigma. In. Perspective in Environmental Health-Vector and Vector Borne Diseases. In: Mukhopadhyay A, De AK, et al. (Eds.), Originals, New Delhi pp: 133-147. 


\section{International Journal of Zoology and Animal Biology}

45. Podder S, Saha GK, Gupta SK (2005) Some new species and new records of dust mites from Kolkata, India. Rec Zool Surv India 104(3\&4): 57-62.

46. Podder S, Gupta SK, Saha GK (2006a) Description of one new species of Grallacheles De Leon (Acari: Cheyletidae) and new records of Pachygnathus Duges (Acari: Pachygnathidae) from floor dust in India. Entomon 31(4): 333-338.

47. Podder S, Choudhury I, Das A (2006b) Occurrence of immediate hypersensitivity to common inhalants an investigation of nasobronchial allergy patients in Kolkata, India. Allergy Clin I 18(3): 114-119.

48. Podder S, Biswas, Gupta SK (2009) Life cycle of house dust mite Dermatophagoides pteronyssinus (Acari:Pyrogylphidae) under laboratory conditions in kolkata metropolis. Acarina 17(2): 219-222.

49. Podder S, Gupta SK, Saha GK (2009) Seasonal prevalence of allergenic mites in house dust of Kolkata Metropolis, India. Aerobiologia 25(1): 39-47.

50. Podder S, Gupta SK, Saha GK (2010) House dust mites in relation to different habitat conditions of Kolkata metropolis, India. Acarina 18(1): 91-95.

51. Podder S, Gupta SK, Saha GK (2010) Incrimination of Blomia tropicalis as a potent allergen in house dust and its role in allergic asthma in Kolkata metropolis, India. Allergy Clin Immunol 3(5): 182-187.

52. Chaudhury S, Roy I, Podder S (2005) Diversity of synanthropic mites in Kolkata Metropolis, India. Rec. zool. Surv. India 104(3-4): 151-159.

53. Chaudhury S, Gupta SK, Saha GK (2011) Seasonal variations in synanthropic mite community of Kolkata, India. Proc Zool Soc 64(1): 35-39.

54. Chaudhury S, Gupta SK, Saha GK (2012) Synanthropic acarine population associated with bird nest. Jr Threat Taxa 4(5): 2553-2616.
55. Chaudhury S, Gupta SK, Saha GK (2013) Synanthropic mites of Kolkata- an ecological appraisal. Proc Zool Soc 66(1): 56-63.

56. Tovey ER, Chapman MD, Platts Mills TAE (1981) Mite faeces are a major source of house dust allergens. Nature 289(5798): 592-593.

57. Halmai Z, Allexander FAR (1971) Studies on the house dust allergen. Allerg Immunol 17: 69-71.

58. Muto K, Takai H, Hiratani M (1985) The increase in serum IgE and anti Dermatophagoides pteronyssinus (anti-DP) specific IgE levels during stay at home in institutionalized asthmatic children: The role of house dust mite in the dwelling as a trigger of asthma attack in mite sensitive patients. Arerugi 34(3): 173183.

59. Kumar L, Newcomb RW, Hornbrook M (1971) A year round study of serum IgE levels in asthmatic children. J Allergy 48(5): 305-312.

60. Khatua SP, Khatua S, Batabayal SK (1986) Immunological study of bronchial asthma. Indian Pediatrics 23: 677-680.

61. Khatua SP, Khatua S, Batabyal SK (1987) Immunological study of bronchial asthma in children. J Pediatric Clinics of India pp: 29-33.

62. Batabyal SK, Ghosh JM, Kundu S (1986) Studies on skin sensitizing tests and serum IgE levels in normal and other allergic disorders. The Antiseptic pp: 37-42.

63. Saha GK, Modak A, Tandon N (1997) Comparative study of dust mite fauna in Calcutta and its suburbs with special reference to Dermatophagoides species. Annals Entomology 15: 18.

64. Modak A, Saha GK, Tandon N (2000) Laboratory observation of the life cycle of Dermatophagoides pteronyssinus (Acarina: Pyroglyphidae): a common allergic mite of house dust. Proc Zool Soc 53(2): 105108. 